\title{
Framing ICT Usage in the Real Estate Industry
}

\author{
Steve Jones, Ph.D. \\ and \\ Zachary Benjamin, M.A. \\ April, 2013 \\ Collaborative Organizations and Social Media
}




\section{Contents}

1. What are ICTs and How are they Disruptive?

2. A Brief Discussion of Methods

3. Analysis

4. Discussion and Suggestions for Future Research. 


\section{Technology, Agency, Disruption, and Productivity: A Literature Review}

- The bulk of the relevant research was conducted between 1998 and 2005, and while enough literature exists to establish a theoretical framework, the body of work is limited.

- Real estate agents traditionally enjoyed the advantage of a cornered market on information. (Crowston and Wigand 1998; Crowston, et al. 2001 and 2005)

- Agents were secure in their role as intermediaries between the consumer and the product. 


\section{Technology, Agency, Disruption, and Productivity: A Literature Review}

- Christensen (1995 and 1997), notes that technologies can be disruptive to industry.

- Some scholars (Bower and Christensen 1995; Markus, et al. 2006) surmise that the increased prevalence of ICTs in various industries can cause individuals and organizations working within them to either adapt accordingly or become obsolete. 


\section{Technology, Agency, Disruption, and Productivity: A Literature Review}

- Rise of information and communication technologies, or ICTs, in the workplace catalyzed process of "disintermediation" (Crowston and Wigand 1999).

- Disintermediation: the removal of the real estate agent as the provider of information and the hub on which consumers must rely for access to property listings. 


\section{Technology, Agency, Disruption, and Productivity: A Literature Review}

- Markus, et al. (2006 and 2008) use the example of the 1980s-2000s mortgage industry, which collectively adopted ICTs to eliminate the need for certain jobs, as an illustration of Christenson's notion of disruptive technologies.

- Markus also identifies framing as a major factor in the success or failure of industry-wide technological implementation:

- "Framing or theorizing of IT innovations...is a process that unfolds over time [and] involves identifying problems; proposing solutions; creating causal arguments; linking problems, solutions, and actions proposed to implement solutions...and rhetorically countering arguments put forth by opponents." (p. 5) 


\section{Technology, Agency, Disruption, and Productivity: A Literature Review}

- Hahn, et al (2005) and Hawker (2006) surmise that real estate agents, though early adopters, will take longer as an industry to adapt to broad ICT adoption because the industry consists of more organizations.

- Kummerow and Lun (2005) and Hawker (2006) surmise that ICTs have lowered the cost of completing a transaction due to increased competition and marketing visibility. 


\section{Technology, Agency, Disruption, and Productivity: A Literature Review}

- Kummerow and Lun's and Hawker's work also indicates that agents' fundamental role has changed as they have adapted to the availability of information to consumers.

- Agents now frame, or position, themselves not simply as intermediaries between buyer and seller, consumer and listing, but as licensed experts with exclusive real estate knowledge, skills, and abilities, without which a successful transaction might be impossible to achieve. 


\section{Research Questions}

- R1: Is technological disruption framed positively or negatively in the literature on ICT usage among real estate agents?

- R2: Do real estate agents positively or negatively frame the phenomenon of ICT usage in their professional interaction? 


\section{Brief Methodological Interlude}

- This study was conducted with mixed qualitative methods, including framing analysis and analysis of literature.

- The first step of conducting this research was a broad survey of the field using JSTOR, Google Scholar, and EBSCO to determine if previous scholarly work existed on the topic of technology usage in the real estate industry. 


\section{Brief Methodological Interlude}

- Very few clues exist as to how agents themselves view technological phenomena and their impact on the profession.

- As a result, we conducted a framing analysis of interviews of National Association of Realtors (NAR) staff conducted between March and July, 2012, by the Creative and Collaborative Information Technology Lab at the University of Illinois at Chicago (UIC). 


\section{Brief Methodological Interlude}

- Due to the fact that the authors attempted to gauge agent sentiment from secondhand sources-in this case, NAR staff members - it was necessary to employ frame alignment, and specifically frame extension, to draw conclusions related to the second research question.

- Frame extension is the expansion of one population's perspective to include another's. 


\section{Analysis of Findings: RQ2}

- 10 interviews reviewed:

- Higher-ranking subjects (senior vice presidents) had broader notions of social network sites as important and beneficial to agents

- Staff working more closely with members (coordinators, specialists, managers) had more specific notions of exactly how agents are using or can continue to use ICTs to build their businesses. 


\section{Analysis of Findings: RQ2}

- Two dominant views regarding agent usage of ICTs:

a. Agents are going through the motions of creating social media profiles and using ICTs, but evidence does not exist that they view these technologies as critical to building and maintaining their cache.

OR

b. NAR members are not only connected, but they are actively engaged, framing ICTs as essential to raising consumer perception of their professional value. 


\section{Analysis of Findings: RQ1}

- Three themes emerge from the literature:

- The rise of ICTs is potentially professionally destructive to real estate agents as consumers gain access to information previously owned exclusively by the agent.

- Disruptive technology is not necessarily destructive to the real estate industry.

- A distinction must be made between the impact of consumer ICT usage and agent ICT usage on the broader real estate industry and the real estate agency profession itself. 


\section{Analysis of Findings: RQ1}

- Two divergent attitudes expressed in the literature:

- a. Crowston, et al. and Bower and Christensen begin the intellectual conversation in the mid-late 1990 s by agreeing in their caution that technology, inherently disruptive, can also be destructive to industry.

\section{HOWEVER}

- b. Later research, especially Hahn (2005), Markus (2005), and Hawker (2006), focuses more intently on the potential benefits of ICT usage by consumers and agents. 


\section{Discussion/Suggestions for Future}

Research

- Several limitations exist to the current research:

- Body of literature on ICTs and their impact on the real estate industry is quite limited.

- Interviews conducted by CCIT team did not include actual practitioners in the field, requiring the authors to draw conclusions from secondhand sources. 


\section{Discussion/Suggestions for Future}

Research

- Multiple opportunities exist for future research:

- Interviews must be conducted with real estate agents in order to gain a more accurate sense of how technologies are being framed within their professional community.

- The impact of variables such as agent age, gender, geographic location, and number of years in the field should be considered. 


\section{Acknowledgment}

- The Creative and Collaborative Information Technology Laboratory (CCIT) at the University of Illinois at Chicago is an interdisciplinary research project specializing in the study of social computing tools in organizations and workplaces in the U.S. This (publication, presentation, report, etc.) is based on work supported in part by the University of Illinois at Chicago College of Business Administration Raising the Research Profile Initiative. Any opinions, findings, and conclusions or recommendations expressed in this publication are those of the authors and do not necessarily reflect the views of the funding agencies, partner or collaborators. 


\section{References}

- $\quad$ Bower, J. and Christensen, C. (2005). Disruptive technologies: Catching the wave. In W.A. Shalman, et al. (Ed.). The entrepreneurial venture. Boston: Harvard University Press.

- Christensen, C. (2007). The Innovator's Dilemma. Boston: Harvard University Press.

- Crowston, K., et al. (1999). Real estate war in cyberspace: An emerging electronic market? International Journal of Electronic Markets, 9, 1-8.

- Crowston, K., et al. (2000). How do information and communication technologies reshape work? Evidence from the residential real estate industry. Proceedings of International Conference on Information Systems. Brisbane, Australia.

- Crowston, K. and Myers, M.D. (2004). Information technology and the transformation of industries: Three research perspectives. Journal of Strategic Information Systems, 13(2004), 5-28.

- Crowston, K. and Myers, M.D. (2004). Will real estate agents survive? The transformation of the real estate industry by information technology. University of Aukland Business Review, 4(2004), 2-13.

- $\quad$ Crowston, K., Sawyer, S. and Wigand, R. (2001). Investigating the Interplay between Structure and Technology in the Real Estate Industry. Proceedings of the Academy of Management Conference.

Chicago, IL.

- $\quad$ Crowston, K. and Wigand, R. (1998). Use of the web for electronic commerce in real estate. Proceedings of the Association for Information Systems Americas Conference. Baltimore, MD.

- Ellison, N.B., et al. (2007). The benefits of Facebook "friends:" Social capital and college students' use of online social network sites. Journal of Computer Mediated Communication, 12, 1143-1168. 


\section{References (Cont'd.)}

- Hahn, R., Litan, R., and Gurman, J. (2005). Paying less for real estate brokerage: What can make it happen? Working Paper 05-11. Washington, DC: AEI-Brookings Joint Center.

- Hawker, N. (2006) Competition in the Residential Real Estate Brokerage Industry: A Report on the AAI Symposium, American Antitrust Institute, Washington, DC, Available online at http://www.antitrustinstitute.org/files/517b.pdf.

- Kummerow, M.L. and Lun, J. (2005). Information and communication technology in the real estate industry: Productivity, industry structure and market efficiency. Telecommunications Policy, 29(2/3), 173-191.

- Markus, M.L., et al. (2006). Industry-wide IS Standardization as Collective Action: The Case of the US Residential Mortgage Industry. MIS Quarterly, 30(4): 439-465.

- $\quad$ Putnam, R.D. (2000). Bowling alone. New York: Simon \& Schuster.

- $\quad$ Sawyer, S., et al. (2003). The social embeddedness of transactions: Evidence from the residential real estate industry. The Information Society, 19, 135-154.

- $\quad$ Sawyer, S., Wigand, R.T., and Crowston, K. (2005). Redefining access: Uses and roles of information and communication technologies in the U.S. real estate industry from 1995-2005. Journal of Information Technology, (00), 1-11.

- Wigand, R., et al (2001). Information and communication technologies in the real estate industry: Results of a pilot survey. Proceedings of the $9^{\text {th }}$ European Conference on Information Systems. Bled, Slovenia. 


\title{
Thank you!
}

\section{Framing ICT Usage in the Real Estate Industry}

\author{
sjones@uic.edu
}

Steve Jones, Ph.D.

and

Zachary Benjamin, M.A. 